\title{
Application of Blockchain Technology and Cryptography Methods to Ensure Economic Security in the Transportation of Crude Oil
}

\author{
Anatoly Makarov, Elena Pisarenko, Gennady Vorobyev \\ Pyatigorsk State University, Pyatigorsk, Russia
}

doi: https://doi.org/10.21467/abstracts.93.95

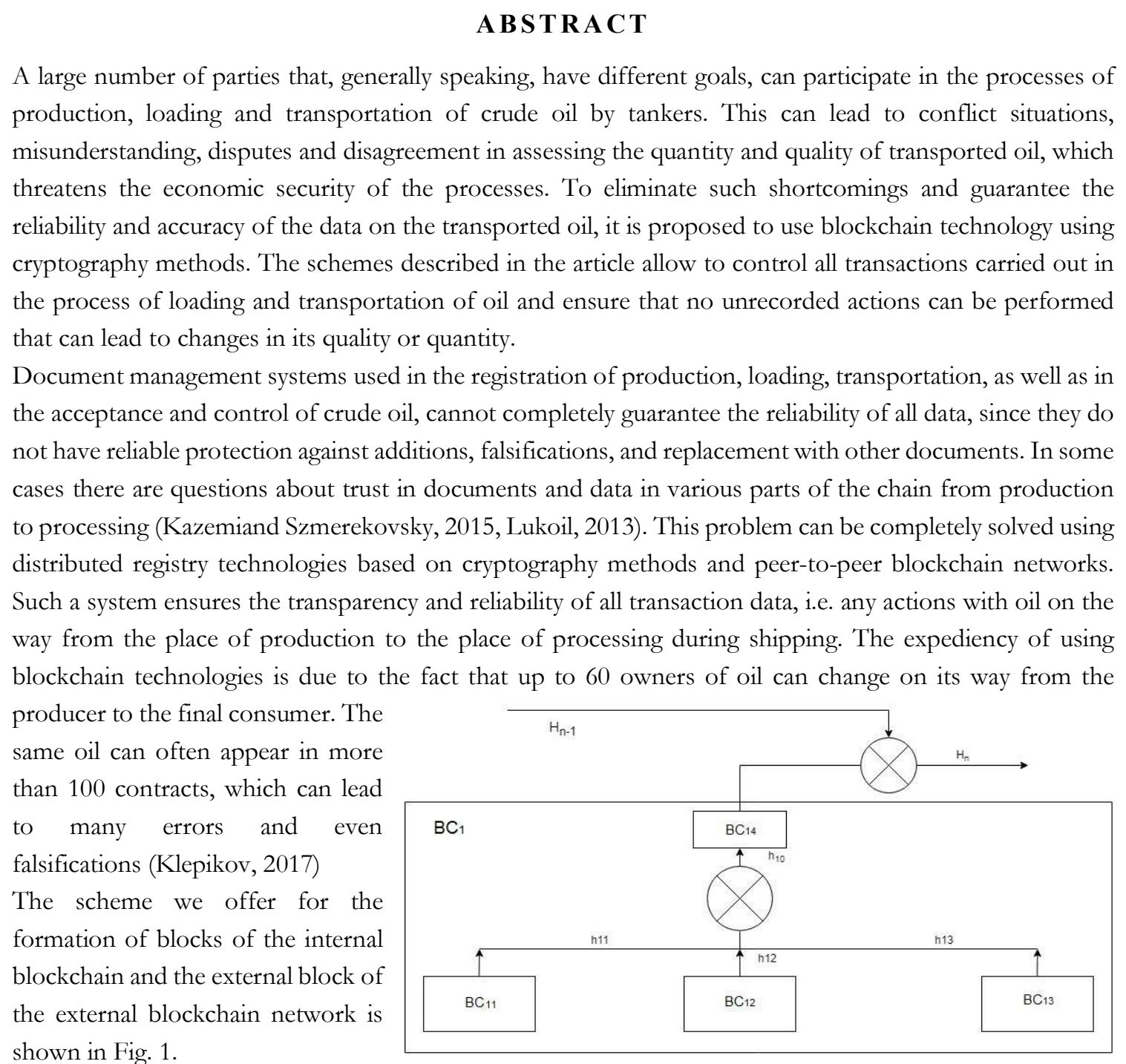

Fig. 1. The composition of the block of the internal blockchain with internal hashes in the external block of the network with a distributed registry

Designations in the figure:

$\mathrm{BC}_{11}$ - the block of data on the origin of crude oil and its geographical location;

$\mathrm{BC}_{12}$ - the block of the set of equipment used in the crude oil production;

$\mathrm{BC}_{13}$ - the block of equipment for measuring the main parameters of crude oil and data on its quantity when transferred to the next link;

(C) 2020 Copyright held by the author(s). Published by AIJR Publisher in "Abstracts of The Second Eurasian RISK-2020 Conference and Symposium" April 12- 19, 2020, Tbilisi, Georgia. Jointly organized by AMIR Technical Services LLC, Georgian Technical University, Institute of Geography (Kazakhstan) and Russian Institute of Petroleum Geology and Geophysics.

DOI: $10.21467 /$ abstracts.93 
The Second Eurasian RISK-2020 Conference and Symposium

$\mathrm{h}_{11}, \mathrm{~h}_{12}, \mathrm{~h}_{13}, \mathrm{~h}_{10}, \mathrm{~h}_{14}$ - internal hashes of blocks $\mathrm{BC}_{11}, \mathrm{BC}_{12}, \mathrm{BC}_{13}, \mathrm{BC}_{14}$;

$\mathrm{h}_{10}$ - the hash uniting blocks $\mathrm{BC}_{11}, \mathrm{BC}_{12}, \mathrm{BC}_{13}$;

$\mathrm{h}_{14}$ - the internal generalizing hashof block $\mathrm{BC}_{14}$;

$\mathrm{h}_{\mathrm{n}}$ - the hash of final block $\mathrm{BC}_{14}$;

$\mathrm{H}_{\mathrm{n}-1}$ - the external hash of the previous block;

$\mathrm{H}_{\mathrm{n}}$ - the external hash number $\mathrm{n}$ of a new block of the network.

The scheme illustrates the formation of an internal block for embedding it in an external network block. The accuracy of the information is fixed by the corresponding hash, which immediately changes when any bit of the BC1, BC2, BC3 blocks is changed, and, most importantly, the filling of the primary space and the tanks of tanker is fixed. Thus, the task of tracking the origin of crude oil, as well as equipment involved in the processes of production, transportation and processing, is solved.

The scheme of the blocks of the external blockchain is shown in Fig. 2.

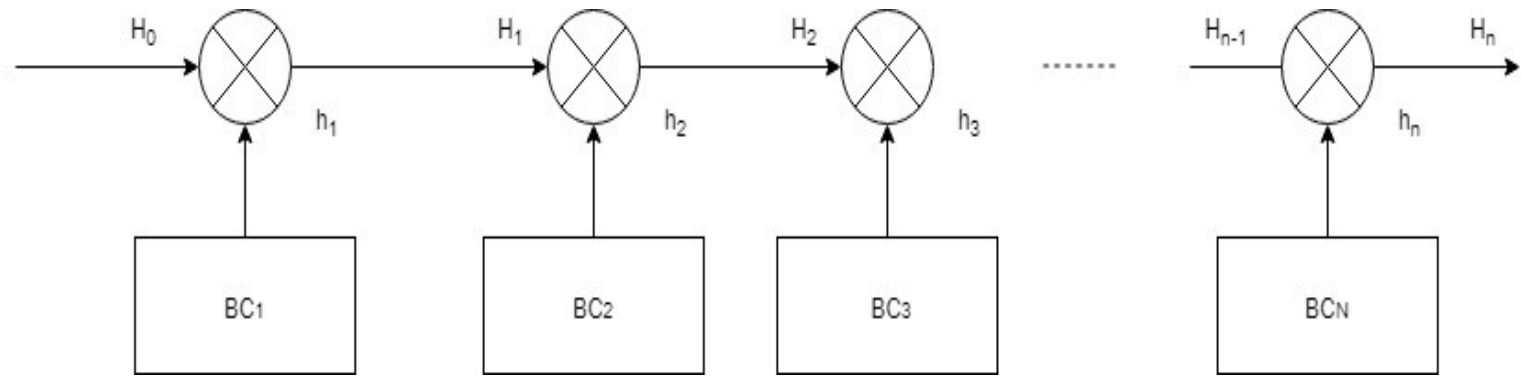

Fig. 2. An example of an external network for generating $H_{n}$ hashes based on internal $h_{n}$

Thus, the data in the blocks are connected by hash functions and in order to change them in the next block, it is necessary to change the hash functions of all previous blocks, and this is almost impossible. The fact thateach network member has the entire database does not allow it to be destroyed or modified.

The considered schemes can be used as a basis for designing networks with a distributed registry (blockchain technologies) using cryptography methods to control all processes of crude oil tanker transportation.

\section{References}

Kazemi, Y., Szmerekovsky, J. Modeling downstream petroleum supply chain: The importance of multi-mode transportation to strategic planning (2015) Transportation Research Part E: Logistics and Transportation Review, 83, pp.111-125, www.elsevier.com/inca/publications/store/6/0/0/2/4/4/, doi: 10.1016/j.tre.2015.09.004

Global Trends in Oil and Gas Markets to 2025, 2017 (2013). http://www.lukoil.be/pdf/Trends_Global_Oil_ENG.pdf

Klepikov, V.P. Development of cargo flows and logistics infrastructure for the transportation of oil cargo in the South of Europe (2017) Logistics and Supply Chain Management, 3(80), pp.77-90. 